\title{
Kajian Kandungan Logam Berat Pada Sedimen Sungai Di Lokasi Penambangan Emas Tradisional, Desa Boto, Kecamatan Jatiroto
}

\section{(Heavy Metal Content Study in River Sediments in Traditional Gold Mining Locations, Boto Village, Jatiroto District)}

\author{
Efendi Putra Dwijaya $\mathrm{Pa}^{1}$, Wawan Budianta ${ }^{1}$, Doni Prakasa Eka Putra ${ }^{1}$ \\ 'Jurusan Teknik Geologi, Fakultas Teknik, Universitas Gadjah Mada
}

\begin{abstract}
Traditional and small-scale gold mining, known as ASGM (Small Scale Gold Mining), has been approved for pollution of the environment specifically for watersheds. This research was conducted in Boto Village, Jatiroto Subdistrict, Wonogiri Regency, Central Java Province. This study discusses the analysis of composition and heavy metals and the factors that support heavy metals in the study site. The samples taken were 22 samples along the river flow in the upstream and downstream areas. Tests of content were not carried out by the ICP-AES method. Laboratory test results on river sediment samples were then analyzed statistically, geoaccumulation index and enrichment factors were calculated. Laboratory test results show that most do not have heavy metal content exceeding the average concentration of heavy metals in river sediments. The spread of heavy metals in river sediments in the study sites was found to be varied with differences in the upstream and downstream areas. In general, upstream areas have higher metal reserves compared to downstream. Distribution of heavy metals for everything that has not been planned, is processed by natural processes or human activities. Traditional mining activities contribute significantly in contributing to the addition of $\mathrm{Hg}$, as well as contributing to the increase of other metals, most of which are in the mineralized area, which fully contains high metal reserves.
\end{abstract}

Keywords: Sediment, heavy metals, ASGM, pollution.

\section{PENDAHULUAN}

Pertambangan emas tradisional dan skala kecil yang dikenal dengan istilah ASGM (Artisanal and Small Scale Gold Mining) merupakan pekerjaan sampingan yang dilakukan oleh masyarakat dengan mata pencaharian utama sebagai petani untuk meningkatkan taraf hidupnya dan umumnya berada di wilayah pedesaan (Nurcholis, dkk., 2017).

Kurangnya pengetahuan masyarakat akan dampak dari kegiatan penambangan seperti ini seringkali mengakibatkan pencemaran maupun kerusakan terhadap lingkungan khususnya daerah aliran sungai. Hal inilah yang terjadi di Desa Boto dan sekitarnya, Kecamatan Jatiroto, Kabupaten Wonogiri, Provinsi Jawa Tengah. Pencemaran logam berat terjadi tidak hanya disebabkan oleh karena aktifitas pertambangan (antropogenik) namun juga oleh faktor alam (geogenik).

\footnotetext{
* Korespodensi Penulis: (Efendi Putra Dwijaya Pa) Jurusan Magister Teknik Geologi, Universitas Gadjah Mada, Yogyakarta.

E-mail: fendypa14@gmail.com
}

Pada peta geologi regional lembar Ponorogo (Sampurno dan Samodra, 1997), dapat dilihat bahwa sesar-sesar yang mendominasi daerah penelitian dan sekitarnya relatif memiliki jurus timurlaut-baratdaya. Menurut Sampurno dan Samodra (1997), mineralisasi berupa bijih sulfida (besi dan tembaga) dijumpai pada urat-urat kuarsa yang memotong batuan gunungapi OligoMiosen di sekitar daerah penelitian. Pada beberapa lokasi, urat kuarsa yang memotong breksi gunungapi mengandung emas dan perak. Alterasi batuan di daerah penelitian dipengaruhi oleh intrusi andesit. Jenis-jenis alterasi yang dijumpai yaitu alterasi argilik, propilitik, silika. Endapan bijih yang dijumpai di daerah penelitian yaitu emas dan galena (Nurcholis, dkk., 2017).

Di daerah penelitian, lokasi penambangan emas berada di daerah perbukitan dengan ketinggian kurang lebih 500 mdpl, sedangkan lokasi pengolahan emas terdapat di sekitar daerah aliran sungai serta pemukiman. Limbah tambang yang dihasilkan biasanya langsung dibuang ke sungai sehingga berpotensi terendapkan dan mencemari air sungai yang merupakan sumber air 
utama untuk irigasi di daerah penelitian.

Menurut Haritsah (2019) daerah penelitian merupakan satuan perbukitan struktural, yang tersusun atas tiga satuan batuan atau litologi yaitu satuan lava andesit, satuan breksi andesit, dan endapan pasir kerakalan.

Untuk itu perlu dilakukan penelitian untuk mengetahui sejauh mana pencemaran oleh logam berat yang sudah terjadi akibat faktor geogenik maupun antropogenik dan hasilnya dapat dijadikan acuan untuk melakukan penanggulangan maupun remediasi.

\section{Lokasi Penelitian}

Lokasi penelitian terletak di daerah Desa Boto, Kecamtan Jatiroto, Kabupaten Wonogiri, Provinsi Jawa Tengah (Gambar 1), merupakan area daerah aliran sungai yang terdapat lokasi penambangan emas tradisional. Koordinat lokasi penelitian ialah berada pada zona UTM (Universal Transverse Mercator) 49S yaitu 517700-520200 dan 9126200-9128200.

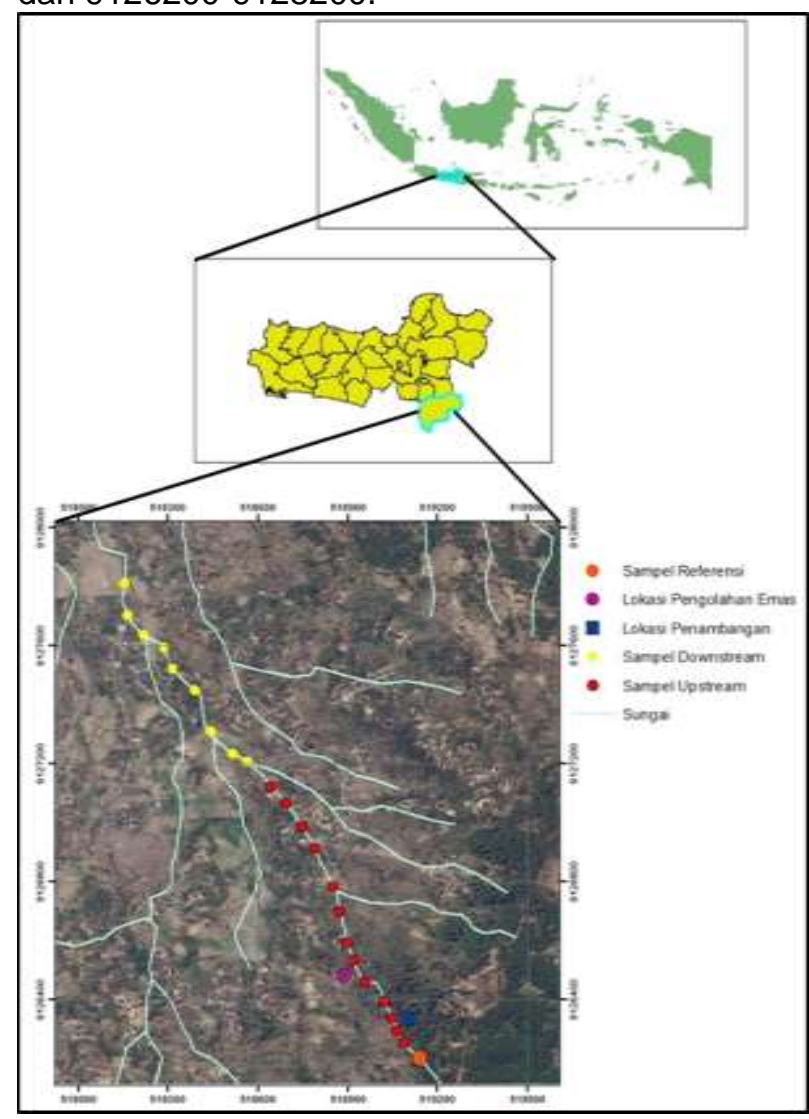

Gambar 1. Peta lokasi penelitian dan pengambilan sampel

Daerah penelitian termasuk dalam zona fisiografi regional Pegunungan Selatan Jawa Timur (van Bemmelen, 1949). Daerah penelitian hanya tersusun oleh satu formasi batuan, yaitu
Formasi Nglanggran (Tmn). Formasi Nglanggran ini terbentuk pada saat volkanisme Andesit Tua atau akhir periode vulkanisme Pegunungan Selatan sehinga batuan penyusunnya didominasi oleh batuan gunungapi. Formasi Nglanggran tersusun atas konglomerat polimik, batupasir kerikilan, batupasir tufan, breksi andesit dengan sisipan tuf dan lava andesit basal. Selain itu, terdapat pula intrusi mikrodiorit atau andesit di beberapa tempat.

\section{METODE}

Pengambilan sampel sedimen sungai diambil di daerah upstream dan downstream sebanyak 22 sampel dan 1 sampel referensi (Gambar 1). Sampel referensi diambil di daerah yang tidak terdapat penambangan dan terindikasi tidak tercemar, sehingga sampel ini dapat dijadikan acuan sebagai keadaan alamiah di daerah penelitian. Prosedur pengambilan sampel yang digunakan mengacu pada metode stream sedimen sampling (British Geological Survey, 2000). Sampel yang telah diambil dianalisis menggunakan ICP-AES (Inductively Coupled Plasma-Atomic Emission Spectroscopy).

Analisis data sampel sedimen sungai dilakukan dengan analisis statistika pada setiap unsur logam berat $\mathrm{As}, \mathrm{Cd}, \mathrm{Pb}, \mathrm{Hg}$. Interpretasi dengan analisis statistika ini mencakup statistika deskriptif, uji normalitas, uji $\mathrm{T}$ ( $t$ test), dan uji korelasi untuk mengetahui sumber logam berat dan faktor-faktor yang mempengaruhi persebaran logam berat dalam sedimen sungai di daerah penelitian.

Analisis indeks geoakumulasi (Igeo) dan faktor pengkayaan (EF) dilakukan melalui perhitungan dari hasil analisis laboratorium sampel sedimen sungai. Hasil perhitungan tersebut akan menghasilkan klasifikasi tingkat pencemaran dan pengkayaan pada sedimen sungai di daerah penelitian. Indeks geoakumulasi digunakan untuk menilai tingkat kontaminasi. Indeks geoakumulasi dapat dihitung dengan rumus di bawah ini :

$$
I_{\text {geo }}=\log _{2}\left(\frac{c_{n}}{1,5 B_{n}}\right)
$$

Keterangan :

Igeo = Indeks geoakumulasi

$\mathrm{C}_{\mathrm{n}}=$ Konsentrasi pada sedimen

$B_{n}=$ Konsentrasi referensi

Faktor pengkayaan (EF) dihitung dengan rumus dibawah ini:

$$
\mathrm{EF}=\frac{\text { Konsentrasi pada sedimen }}{\text { Konsentrasi referensi material }}
$$




\section{HASIL DAN PEMBAHASAN}

\section{Deskripsi Statistika}

Hasil analisis ICP-AES (Inductively Coupled Plasma-Atomic Emission Spectroscopy) kandungan unsur $\mathrm{As}, \mathrm{Cd}, \mathrm{Pb}$ dan $\mathrm{Hg}$ pada sedimen sungai pada 22 titik lokasi pengambilan sampel di daerah penelitian serta 1 sampel referensi $(\mathrm{Bn})$ yang akan digunakan untuk perhitungan indeks geoakumulasi (Igeo) dan faktor pengkayaan (EF) yang ditunjukkan pada Tabel 1.

Tabel 1. Hasil analisis logam berat sedimen sungai (ppm)

\begin{tabular}{|c|c|c|c|c|}
\hline Kode & As & $\mathrm{Cd}$ & $\mathrm{Pb}$ & $\mathrm{Hg}$ \\
\hline $\mathrm{Bn}$ & 6,9 & 0,2 & 23,3 & 0,02 \\
\hline $\mathrm{Bl}$ & 12,4 & 1,2 & 100,5 & 9,6 \\
\hline B2 & 56,5 & 1,5 & 67,6 & 8,9 \\
\hline B3 & 175,5 & 1,7 & 28,9 & 6,7 \\
\hline B4 & 11,8 & 2,2 & 200,1 & 7,8 \\
\hline B5 & 15,1 & 1,6 & 124,5 & 6,2 \\
\hline B6 & 4,5 & 0,9 & 89,5 & 4,2 \\
\hline B7 & 9,8 & 4,3 & 498,9 & 3,4 \\
\hline B8 & 10,4 & 1,2 & 508 & 3,7 \\
\hline B9 & 12,2 & 3,1 & 92,7 & 6,6 \\
\hline $\mathrm{Bl0}$ & 9,6 & 0,3 & 14,7 & 7,8 \\
\hline Bll & 5,4 & 3,2 & 9,5 & 8,1 \\
\hline $\mathrm{B} 12$ & 3,7 & 2,2 & 383,5 & 7,1 \\
\hline B13 & 11,9 & 2,1 & 56,7 & 4,5 \\
\hline B14 & 10 & 0,8 & 23,4 & 7,6 \\
\hline $\mathrm{Bl5}$ & 6,6 & 0,9 & 89,7 & 7,6 \\
\hline $\mathrm{Bl} 6$ & 7,8 & 3,2 & 23,2 & 6,6 \\
\hline $\mathrm{Bl7}$ & 10,3 & 0,5 & 17,3 & 4,5 \\
\hline B18 & 9,9 & 1,1 & 76,4 & 6,5 \\
\hline $\mathrm{B} 19$ & 6,4 & 1,2 & 10,4 & 0,9 \\
\hline B20 & 7,2 & 1,2 & 23,4 & 1,9 \\
\hline B21 & 9 & 0,2 & 11,2 & 2,1 \\
\hline B22 & 7,1 & 0,1 & 9 & 3,1 \\
\hline Rata-rata & 18,78 & 1,58 & 111,78 & 5,70 \\
\hline $\begin{array}{c}\text { Rata-rata kerak } \\
\text { bumi (Reiman dan } \\
\text { Caritat,1998) }\end{array}$ & 2 & 0,1 & 17 & 0,05 \\
\hline $\begin{array}{l}\text { Rata-rata sedimen } \\
\text { (Reiman dan } \\
\text { Caritat,1998) } \\
\end{array}$ & 2 & - & 26 & - \\
\hline
\end{tabular}

Sedangkan pada Gambar 2 menunjukkan pola persebaran unsur $\mathrm{As}$ dan $\mathrm{Pb}$ pada sedimen sungai. Secara umum unsur As memiliki pola yaitu memiliki kecenderungan nilai yang tinggi pada area upstream dan semakin rendah di area downstream sungai. Nilai unsur As yang tinggi terdapat pada lokasi pengambilan sampel B1 sampai B5 dimana lokasi tersebut adalah lokasi yang dekat dengan lokasi penambangan sedangkan nilai unsur As yang rendah berada pada lokasi yang jauh atau tidak ada kegiatan penambangan.

Unsur $\mathrm{Pb}$ memiliki nilai tinggi di daerah upstream, namun lokasi yang lain relatif tidak bervariasi karena tidak terdapat kenaikan atau penurunan yang signifikan. Unsur $\mathrm{Pb}$ memiliki pola yaitu nilai tinggi pada lokasi pengambilan sampel B7 dan B8 kemudian memiliki nilai terendah pada lokasi pengambilan sampel B22.

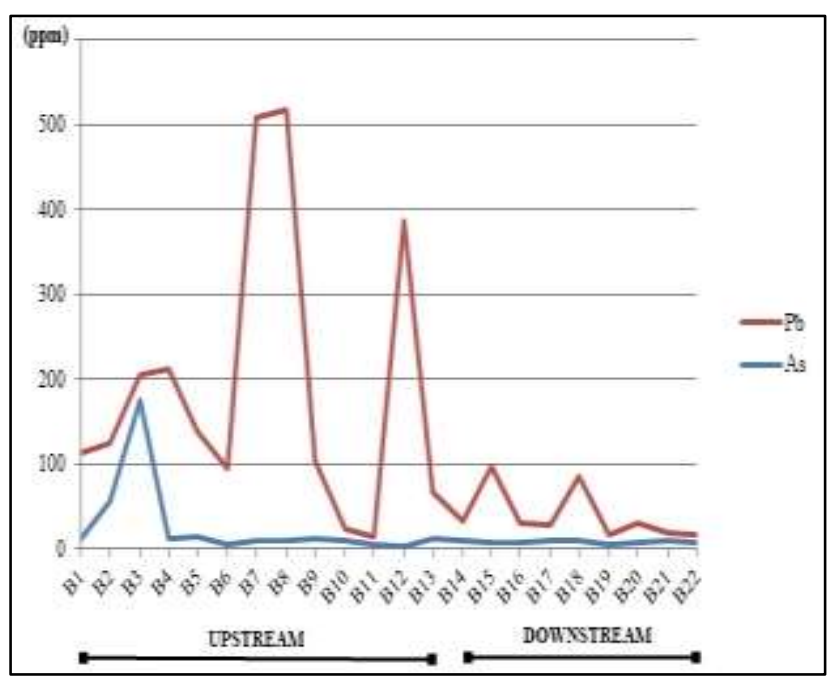

Gambar 2. Grafik Persebaran As dan $\mathrm{Pb}$

Pola persebaran unsur $\mathrm{Cd}$ dan $\mathrm{Hg}$ pada sedimen sungai (Gambar 3). Unsur Cd memiliki pola yang sama yaitu memiliki nilai cenderung merata di setiap lokasi. Nilai unsur $\mathrm{Cd}$ mengalami penurunan pada lokasi pengambilan sampel B17 sampai B22 dimana lokasi tersebut adalah lokasi terjauh dari lokasi kegiatan penambangan dan juga tempat tinggal masyarakat.Pola persebaran unsur $\mathrm{Hg}$ juga mempunyai kecenderungan nilai semakin mengecil menuju area downstream. Nilai tertinggi ada pada lokasi pengambilan sampel B1 yaitu di area upstream kemudian mengalami penurunan pada lokasi pengambilan sampel B7, mengalami kenaikan kembali pada lokasi pengambilan sampel B11 dan kemudian mengalami penurunan kembali hingga lokasi pengambilan sampel B22.

\section{Uji T ( $t$ test)}

T-test digunakan untuk mengetahui adanya suatu perbedaan antara dua jenis data. Pada penelitian ini analisis $t$ test dilakukan untuk mengetahui perbedaan pada area upstream dan downstream untuk masing-masing parameter di sedimen sungai. Parameter yang memiliki nilai Sig. (2-tailed) kurang dari 0,05 menunjukkan parameter yang memiliki perbedaan sigmifikan 
antara upstream dan downstream. Parbedaan antara upstream dan downstream tetap ada walaupun tidak signifikan, ini bisa kita lihat pada nilai mean pada Tabel 2, nilai mean yang tinggi menunjukan bahwa parameter memiliki kandungan yang lebih tinggi dibandingkan yang mempunyai nilai mean rendah.

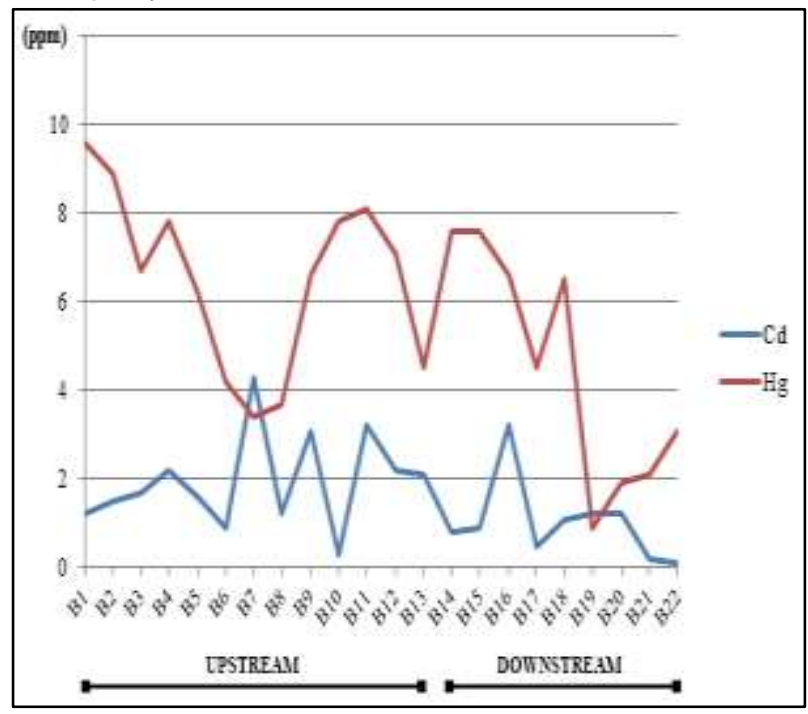

Gambar 3. Grafik Persebaran Cd dan Hg

Adanya aktifitas penambangan dan pengolahan emas menggunakan metode amalgamasi menjadi penyebab perbedaan karakteristik kandungan beberapa logam berat di upstream dan downstream pada sedimen sungai. Adanya perbedaan karakteristik logam berat antara area upstream dan downstream dipengaruhi oleh aktifitas penambangan dan pengolahan emas dengan metode amalgamasi di area upstream dimana semakin menuju downstream nilai logam berat relatif semakin mengecil karena semakin jauh dengan sumber pencemar.

Tabel 2. Hasil t test analisis untuk sedimen sungai

\begin{tabular}{|c|c|c|c|c|}
\hline Parameter & Jenis Kelompok & Mean & Sig. (2-tailed) & Perbedaan \\
\hline \multirow{2}{*}{ As } & Upstreem & 26,06 & \multirow{2}{*}{0,271} & Tidak \\
\hline & Downstream & 8,25 & & Signifikan \\
\hline \multirow{2}{*}{$\mathrm{Cd}$} & Upstrean & 1,96 & \multirow{2}{*}{0,045} & \multirow{2}{*}{ Signifikan } \\
\hline & Downstream & 1,02 & & \\
\hline \multirow{2}{*}{$\mathrm{Pb}$} & Upstrean & 167,31 & \multirow{2}{*}{0,036} & \multirow{2}{*}{ Signifikan } \\
\hline & Dornstream & 31,55 & & \\
\hline \multirow{2}{*}{$\mathrm{Hg}$} & Upstrean & 6,50 & \multirow{2}{*}{0,059} & \multirow{2}{*}{$\begin{array}{c}\text { Tidak } \\
\text { Signifikan }\end{array}$} \\
\hline & Downstrem & 4,53 & & \\
\hline
\end{tabular}

Analisis Korelasi

Analisis korelasi digunakan pada analisis logam berat di sedimen sungai untuk mengetahui hubungan antara masing-masing logam berat yang terkandung dalam sedimen sungai. Berdasarkan tabel 3 dapat diketahui bahwa terdapat unsur yang memiliki hubungan korelasi cukup adalah $\mathrm{Pb}$ dan $\mathrm{Cd}$. Hubungan atau korelasi yang kuat antara logam yang berbeda menunjukkan sumber yang umum, saling ketergantungan dan perilaku yang identik selama proses transport. Namun, tidak adanya hubungan atau korelasi yang kuat antara beberapa logam ini menunjukkan sumber antrophogenik dan geogenic yang berbeda (Ren,dkk 2015). Analisis korelasi dilakukan untuk menilai kemungkinan sumber yang identik dari logam berat. Logam berat dengan hubungan atau korelasi yang positif dianggap memiliki sumber yang sama (Moore dan Attar, 2011). Hal tersebut menunjukkan bahwa adanya hubungan atau korelasi yang cukup antara unsur-unsur $\mathrm{Pb}$ dan $\mathrm{Cd}$ dipengaruhi oleh adanya kesamaan sumber yaitu bersumber pada proses mineralisasi pada batuan beku di lokasi penelitian.

Unsur As dan $\mathrm{Hg}$ memiliki korelasi yang lemah karena sumber unsur $\mathrm{Hg}$ yang secara dominan bersumber dari aktivitas pengolahan emas (antrophogenik) sedangkan unsur As memang sudah tinggi secara alamiah (geogenic) di daerah penelitian, ditambah adanya aktivitas penambangan (antrophogenik).

Tabel 3. Hasil analisis korelasi sedimen sungai

\begin{tabular}{cccccc}
\hline \multirow{2}{*}{ N } & \multirow{2}{*}{ Cusur } & \multicolumn{4}{c}{ Unsur } \\
\cline { 3 - 6 }$n$ & & As & $\mathrm{Cd}$ & $\mathrm{Pb}$ & $\mathrm{Hg}$ \\
$n$ & As & 1 & 0,024 & $-0,132$ & 0,186 \\
$n$ & $\mathrm{Cd}$ & 0,024 & 1 & $0,417^{*}$ & 0,173 \\
$n$ & $\mathrm{~Pb}$ & $-0,132$ & $0,417^{*}$ & 1 & $-0,064$ \\
$n$ & $\mathrm{Hg}$ & 0,186 & 0,173 & $-0,064$ & 1 \\
\hline
\end{tabular}

*Signifikan 0,05

Faktor Pengkayaan Dan Indeks Geoakumulasi

Perhitungan Indeks geoakumulasi (Igeo) rata-rata seluruh sampel dihitung dengan cara memasukan nilai rata-rata tiap unsur pada tabel 1 ke rumus (1), selanjutnya sesuai hasil perhitungan yang ada dapat dilakukan klasifikasi kelas indeks geoakumulasi untuk mengetahui kualitaas sedimen sungai di daerah penelitian. Sedangkan untuk perhitungan Faktor Pengkayaan rata-rata sampel dapat dihitung dengan cara memasukan nilai rata-rata tiap unsur pada tabel 1 ke rumus (2) dan hasil perhitungan tersebut dapat dilakukan klasifikasi kriteria faktor pengkayaan. 
Tabel 4. Hasil Perhitungan dan Klasifikasi Indeks Geoakumulasi serta Faktor Pengkayaan

\begin{tabular}{|c|c|c|c|c|}
\hline Unsur & $\mathrm{EF}$ & $\begin{array}{c}\text { Kriteria Faktor } \\
\text { pengkayaan } \\
\text { (Sutherland, 2000) }\end{array}$ & Igeo & $\begin{array}{l}\text { Kualitas Sedimen } \\
\text { (Eby,2004) }\end{array}$ \\
\hline As & 2,7 & Pengkayaan sedang & 0,55 & $\begin{array}{l}\text { Tidak tercemar sampai } \\
\text { tercemar sedang }\end{array}$ \\
\hline $\mathrm{Cd}$ & 7,9 & Pengkayaan cukup & 1,58 & Tercemar sedang \\
\hline $\mathrm{Pb}$ & 4,8 & Pengkayaan sedang & 0,96 & $\begin{array}{l}\text { Tidak tercemar sampai } \\
\text { tercenar sedang }\end{array}$ \\
\hline $\mathrm{Hg}$ & 285 & $\begin{array}{c}\text { Pengkayaan sangat } \\
\text { tinggi }\end{array}$ & 57,20 & Tercemar sangat tinggi \\
\hline
\end{tabular}

Berdasarkan nilai indeks geoakumulasi rata-rata konsentrasi $\mathrm{As}$ dan $\mathrm{Pb}$ pada tabel 4 dapat terlihat bahwa tingkat pencemaran sedimen sungai di daerah penelitian akibat konsentrasi As dan $\mathrm{Pb}$ berada pada kategori tidak tercemar sampai tercemar sedang.

Untuk faktor pengkayaan konsentrasi As dan $\mathrm{Pb}$ termasuk dalam kriteria pengkayaan sedang (moderate) karena rata-rata nilai faktor pengkayaannya yang berkisar antara 2 sampai 5 .

Nilai indeks geoakumulasi rata-rata konsentrasi $\mathrm{Cd}$ menunjukan bahwa pencemaran sedimen sungai di daerah penelitian karena konsentrasi $\mathrm{Cd}$ berada pada kategori tercemar sedang dan faktor pengkayaan konsentrasi $\mathrm{Cd}$ termasuk dalam kriteria pengkayaan cukup (significant) karena memiliki nilai rata-rata faktor pengkayaan 5 sampai 20.

Untuk rata-rata konsentrasi $\mathrm{Hg}$, nilai indeks geoakmulasinya mempunyai nilai $>5$, yang berarti tingkat pencemaran sedimen sungai di daerah penelitian akibat konsentrasi $\mathrm{Hg}$ berada pada kategori tercemar sangat tinggi. Nilai faktor pengkayaan rata-rata konsentrasi $\mathrm{Hg}$ yaitu 285 , nilai ini $>40$ yang berarti bahwa konsentrasi $\mathrm{Hg}$ telah masuk kriteria pengkayaan yang sangat tinggi (extremely high).

Hasil analisis sampel urat dan rata-rata kandungan logam berat pada kerak bumi seperti yang terlihat pada tabel 5 jika dibandingkan, menunjukkan bahwa kandungan unsur-unsur pada batuan di lokasi penelitian memang sudah tinggi dan hal ini bisa diakibatkan oleh adanya proses alterasi (geogenic).

Tabel 5. Hasil analisis logam berat pada sampel urat (ppm)

\begin{tabular}{ccccc}
\hline Code & As & $\mathrm{Cd}$ & $\mathrm{Pb}$ & $\mathrm{Hg}$ \\
\hline Urat & 89,5 & 110,5 & 18,9 & 0,1 \\
$\begin{array}{c}\text { Rata-rata kerak bumi } \\
\text { (Reiman dan Caritat,1998) }\end{array}$ & 2 & 0,1 & 17 & 0,05 \\
\hline
\end{tabular}

Sedangkan perbedaan nilai faktor pengkayaan pada beberapa unsur yang cenderung lebih besar pada sampel yang berdekatan dengan kegiatan penambangan yang mana berada di daerah upstream menjadi indikasi bahwa proses pengkayaan juga disebabkan oleh adanya kegiatan penambangan yang menyebabkan tersingkapnya batuan dan pengolahan emas dengan metode amalgamasi. Sehingga dapat disimpulkan adanya proses pengkayaan pada beberapa unsur di lokasi penelitian disebabkan oleh proses alami yaitu proses alterasi (geogenic) dan didukung dengan adanya kegiatan penambangan dan pengolahan emas (antrophogenic).

\section{KESIMPULAN}

Penyebaran logam berat di sedimen sungai di lokasi penelitian dipengaruhi oleh proses alamiah maupun kegiatan manusia yang bervariasi dengan adanya perbedaan pada area upstream dan downstream. Secara umum, daerah upstream mempunyai kandungan logam berat yang lebih tinggi jika dibandingkan dengan di downstream.

\section{UCAPAN TERIMA KASIH}

Penulis mengucapkan limpah terimakasih kepada Departemen Teknik Geologi Universitas Gadjah Mada Yogyakarta yang telah membantu pendanaan penelitian ini. Penulis juga mengucapkan terimakasih kepada Tokyo Institute of Technology yang telah membantu dalam analisis sampel.

\section{DAFTAR PUSTAKA}

British Geological Survey, 2000, Stream Sediment Sampling

https://www.bgs.ac.uk/downloads/start. cfm?id=1319

Eby, G.N., 2004, Principles of Environment Geochemistry, Brooks/ Cole Thomson Learning, Southbank.

Haritsah, L., 2019. Kajian Kandungan Logam Berat Dalam Air Sungai Pada Lokasi Penambangan Emas Tradisional Dan Skala Kecil Di Desa Boto Dan Sekitarnya, Kecamatan Jatiroto, Kabupaten Wonogiri, Provinsi Jawa Tengah. Skripsi Jurusan Teknik Geologi Fakultas Teknik UGM, Yogyakarta (Tidak dipublikasikan). 
Moore, F., Attar, A. 2011. Antrophogenic Source of Heavy Metals in Deposited Sediments From Runoff and Industrial Effluents, Shiraz, Sw, Iran. 2nd International Conference on Enviromental Scince and Technology, IPCBEE Vol. 6.

Nurcholis, M., Yudiantoro, D.F., Haryanto, D., and Mirzam, D., 2017, : Heavy Metals Distribution in the Artisanal Gold Mining Area in Wonogiri, Indonesian Journal of Geography, Vol. 49, No.2

Reiman, C \& Caritat, P,. 1998, Chemical Elements in The Environent, Springer.

Ren, J., Shang, Z., Tao, L., Wang, X. 2015. Multivariate Analysis and Heavy
Metals Pollution Evaluation in Yellow River Surface Sediments. Pol. J. Environ. Stud. Vol. 24, No 3.

Sampurno and Samodra, H., 1997, Geological map of the Ponorogo Quadrangle, Java. Geological Research and Development Center, Bandung

Sutherland, R.A, 2000, Bed sediment-associated trace metals in an urban stream, Oahu, Hawaii, Journal of Environmental Geology, Vol. 39: $611-37$.

Van Bemmelen, R.W. (1949). The Geology of Indonesia. Vol IA, Government Printing Office, hal. 28-29, 102-106, 595-602. 